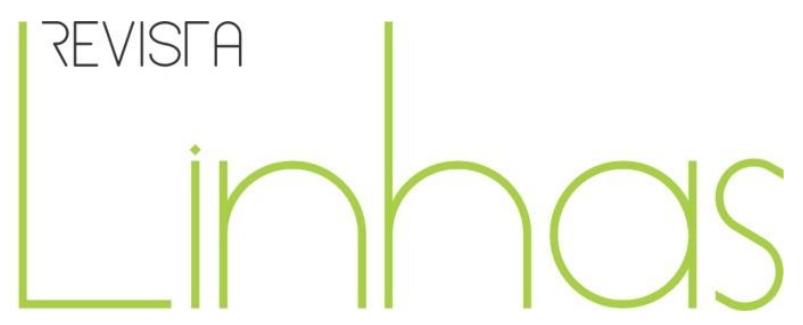

\title{
Disciplinas que discutem sexualidade nos currículos do Ensino Superior brasileiro: produzindo um diagnóstico da situação atual
}

\begin{abstract}
Resumo
Este artigo tem como objetivo apresentar um panorama acerca da emergência de disciplinas que discutem a sexualidade no âmbito das universidades federais brasileiras. A fim de conhecer e refletir sobre essa emergência, realizamos um levantamento, que denominamos como mapeamento, com o propósito de conhecer quais universidades federais do Brasil oferecem disciplinas relacionadas a essas temáticas. Esse levantamento foi realizado nas cinco regiões brasileiras - Norte, Nordeste, Centro-Oeste, Sudeste e Sul - e em todas as universidades federais devidamente credenciadas no Ministério da Educação (MEC). Na pesquisa, levamos em consideração os cursos de graduação em licenciatura, bacharelado e tecnólogos. A partir da produção do panorama da incidência dessas disciplinas, foi possível refletir à luz das discussões traçadas por Foucault sobre a tecnologia de poder, que tem como objetivo a regulamentação da população. Pensar tais disciplinas enquanto integrantes de estratégias biopolíticas nos fez perceber o quanto essa tecnologia de poder vem adquirindo cada vez mais vitalidade e visibilidade na contemporaneidade. Ademais, também foi possível pensar as relações de poder e saber implicadas na produção dos currículos do ensino superior. De tal maneira, a partir de alguns rastros presentes na história da sexualidade e a partir de um diagnóstico dessa atual situação evidenciada na produção do mapeamento, buscamos compreender o presente, ou seja, os efeitos, na contemporaneidade, de disciplinas que discutem a sexualidade no âmbito das universidades federais do país.
\end{abstract}

Palavras-chave: Sexualidade; Ensino Superior; Disciplina.

\author{
Juliana Lapa Rizza \\ Universidade Federal do Rio \\ Grande - FURG - RS/Brasil \\ ju_rizza@yahoo.com.br
}

Paula Regina Costa Ribeiro Universidade Federal do Rio Grande - FURG - RS/Brasil pribeiro.furg@gmail.com

Maria Renata Alonso Mota Universidade Federal do Rio Grande - FURG - RS/Brasil mariarenata.alonso@gmail.com

\section{Para citar este artigo:}

RIZZA, Juliana Lapa; RIBEIRO, Paula Regina Costa; MOTA, Maria Renata Alonso. Disciplinas que discutem sexualidade nos currículos do Ensino Superior brasileiro: produzindo um diagnóstico da situação atual. Revista Linhas. Florianópolis, v. 17, n. 34, p. 197-224, maio/ago. 2016. 


\title{
Academic subjects that discuss sexuality in brazilian Higher Education curriculum: producing a diagnosis of the current situation
}

\begin{abstract}
This article aims to present an overview about the emergence of academic subjects that discuss sexuality within the Brazilian federal universities. In order to understand and reflect on this occurrence, we conducted an investigation, which we referred to as mapping, with the purpose of knowing which federal universities in Brazil offer subjects related to these themes. This survey was conducted in the five Brazilian regions - North, Northeast, Midwest, South and Southeast - and in all federal universities duly recognized by the Brazilian Ministry of Education (MEC). In the study, we took into consideration licentiate, bachelor and technology undergraduate courses. From the production of the scenery of the disciplines' incidence, it was possible to reflect, from the discussions outlined by Foucault, on the technology of power, which aims to regulate the population. Considering such academic subjects as members of biopolitical strategies made us realize how much vitality and visibility this technology of power has been increasingly gaining nowadays. Furthermore, it was also possible to think of power and knowledge relations involved in the production of higher education curricula. Consequently, from some traces present in the history of sexuality and from a diagnosis of this current situation evidenced in the mapping, we sought to understand the present, i.e., the effects, in the contemporaneity, of the academic subjects that discuss sexuality within federal universities in the country.
\end{abstract}

Keywords: Sexuality; Higher Education; Discipline. 


\section{Introdução}

Na contemporaneidade, é possível observar um significativo movimento da sexualidade sendo tema de debate no ensino superior. Dentre os espaços de discussão da sexualidade, nesse nível de ensino estão: cursos de extensão, palestras, eventos, atuação dos grupos de pesquisa com o desenvolvimento de atividades e ações para repensar as questões que envolvem essa temática, e essas, dentre outras estratégias, têm possibilitado algumas discussões da sexualidade nas universidades.

No entanto, temos observado também a incidência de outros espaços. Estamos nos referindo, especialmente, às disciplinas que discutem as questões de sexualidade e que vêm sendo ofertadas em algumas universidades federais do Brasil na modalidade obrigatória e, em outras, como optativa. Essas disciplinas são oferecidas em diferentes cursos de graduação e apresentam distintas abordagens: tratam das questões de gênero, saúde, cuidados com o corpo, diversidade em diferentes enfoques - de sexo, de raça, de etnia, de gênero -, aspectos sociais, políticos, econômicos, históricos e culturais.

Esse cenário da sexualidade, sendo abordada nas universidades, por meio de disciplinas, em diferentes cursos de graduação se produz a partir de alguns movimentos que vêm ocorrendo nos últimos anos com relação ao debate da sexualidade em diferentes âmbitos - educacionais e sociais -, que se refletem em práticas e problematizações também no ensino superior. Dentre eles, podemos destacar: implementação de políticas públicas as quais têm apresentado a importância de pensarmos as questões da diversidade de gênero e sexuais nas instituições escolares; ações do Ministério da Educação (MEC) para a inclusão dessas questões nos currículos escolares e universitários, dentre elas a criação da Secretaria de Educação Continuada, Alfabetização, Diversidade e Inclusão (SECADI); as discussões propostas pelo eixo transversal Orientação Sexual presente nos Parâmetros Curriculares Nacionais (PCN) que emergem na década de 1990; o aumento da violência sexista, racial e homofóbica; as múltiplas identidades que têm se apresentado nas escolas e universidades, como os/as travestis e os/as transexuais; a utilização do nome social; entre outros aspectos.

A partir do olhar que lançamos para os aspectos sociais, históricos e culturais acerca da discussão da sexualidade, é possível perceber esses movimentos. Um olhar que 
não se propõe desvelar, mostrar o que está oculto ou ainda trazer à tona o que foi silenciado. Lançar mão de outros olhares, esse é o desafio a que nos propomos nessa escrita, olhares para os currículos das universidades brasileiras e seus atravessamentos com a temática da sexualidade, os quais entendem que "as imagens que o mundo, principalmente social, apresenta, a rigor, ele não apresenta isentamente, isto é, é o olhar que botamos sobre as coisas que, de certa maneira, as constiui" (VEIGA-NETO, 2007a, p. 30).

Não há distanciamento e neutralidade nesse processo; o olhar que lançamos sobre essas disciplinas está imbricado com nossas vivências, ou seja, nossa forma de ver e compreender o mundo e as relações que nele se estabelecem. Sendo assim, dentre as estratégias possíveis de lançar esse olhar para os dados, deparamo-nos com as que têm como objetivo olhar para história a fim de compreender o presente, proposta vinda com Foucault com seus estudos genealógicos. Nossa pretensão não é investir em um estudo genealógico assim como o realizado pelo filósofo; temos como proposta, a partir de algumas inspirações da genealogia, com a utilização de algumas ferramentas desse campo de estudo, olhar para os rastros históricos a fim de compreender os movimentos que foram ocorrendo e que possibilitaram que, na contemporaneidade, nos deparássemos com a emergência de disciplinas que tratam da sexualidade no ensino superior.

No entanto, ao olhar para a história, trata-se não de contar fatos históricos passados, revivendo-os quase como em uma linha do tempo com o propósito de comprovar vivências do presente. É uma história diferente, uma forma especial de fazer história (VEIGA-NETO, 2007), ““escrever a história do presente’ é outra coisa. Essa abordagem começa de forma explícita e reflexiva com um diagnóstico da situação atual” (DREYFUS; RABINOW, 2010, p. 158).

Para escrever essa história do presente, é preciso, primeiramente, produzir um diagnóstico da atual situação, e é a partir dessa proposta que este artigo passa a ser produzido; ou seja, com objetivo de apresentar um panorama acerca da emergência dessas disciplinas no âmbito das universidades federais brasileiras. Fizemos um investimento a fim de conhecer as universidades federais, localizadas em diferentes estados brasileiros, com distintos cursos de graduação, e que estão oferecendo 
disciplinas que discutem a sexualidade; para tanto, produzimos então um mapeamento acerca desse movimento que vem ocorrendo no ensino superior. ${ }^{1}$

\section{Produzindo um panorama da sexualidade no ensino superior: um olhar para as disciplinas nas universidades brasileiras}

Vestir nossos óculos teóricos e aguçar nossas lentes, ou seja, a partir dos nossos entendimentos e leituras, buscamos lançar nosso olhar para as disciplinas nas universidades federais brasileiras e, a partir desse investimento, foi possível construir um panorama da sexualidade no ensino superior.

O mapeamento foi realizado nas cinco regiões brasileiras - Norte, Nordeste, Centro-Oeste, Sudeste e Sul, em todas as universidades federais credenciadas pelo Ministério da Educação, produzindo-se assim um diagnóstico dessa atual situação.

Através do site do MEC é possível encontrar no link IES (Instituições de Ensino Superior) as universidades credenciadas no MEC. O espaço, "e-mec", presente no site, foi implementado em 2007 com o propósito de registrar os trâmites de credenciamento, recredenciamento, autorização, reconhecimento e renovação de reconhecimento dos cursos das Instituições de ensino superior (BRASIL, 2012), é o sistema eletrônico que permite o acompanhamento dos processos de regulamentação das instituições.

Para buscar pelas disciplinas, foi estabelecido um critério: a presença na nomenclatura das disciplinas de uma das seguintes palavras-chave: gênero, diversidade, sexualidade, educação sexual e orientação sexual. Quando encontradas uma dessas palavras na nomenclatura das disciplinas, a mesma já era selecionada.

O mapeamento foi realizado por meio dos sites das instituições, totalizando 60 universidades federais pesquisadas no Brasil. Do total pesquisado, em 44 instituições foi possível ter acesso aos currículos dos cursos de graduação, o equivalente a 73\%, e em 16 instituições, cerca de $27 \%$, não obtivemos acesso, o que nos impossibilitou saber se havia disciplinas de sexualidade sendo ministradas, como é possível perceber na Gráfico 1.

\footnotetext{
1 Este texto integra uma pesquisa ampliada relacionada à Tese de Doutorado, do Programa de PósGraduação em Educação Ambiental da Universidade Federal do Rio Grande - FURG.
} 


\section{Gráfico 1- Acesso aos currículos das instituições}

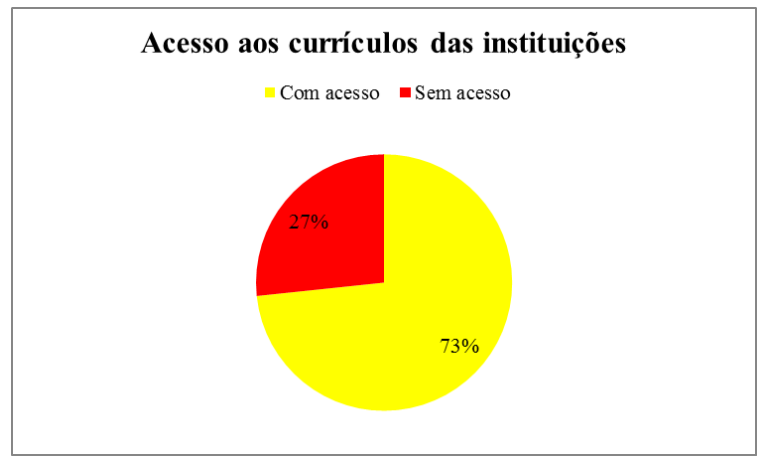

Fonte: Autoria pessoal, 2013.

Foram investigados os cursos de graduação de: Licenciatura, Bacharelado e Tecnólogo. Além disso, as instituições que possuem mais de um campus/campi tiveram todas as suas unidades analisadas.

Por meio dos seguintes achados do mapeamento: número de universidades que oferecem disciplinas; relação de disciplinas que vêm sendo ofertadas; quais áreas de conhecimento - cursos de graduação - têm ofertado disciplinas e, por fim, o caráter das disciplinas - obrigatório ou optativo -, foi possível compreender alguns desses movimentos que vêm ocorrendo nos currículos do ensino superior em relação à discussão da sexualidade.

Ao lançar nosso olhar para esses currículos que têm ofertado disciplinas que tratam da sexualidade, um dos dados apresentou-se como significativo para o investimento nesse estudo. Dentre as 44 universidades em que foi possível analisar os currículos dos cursos de graduação ofertados, 38 dessas instituições oferecem disciplinas, o que corresponde a $86 \%$, e somente 6 não oferecem disciplinas, o equivalente a $14 \%$, como é possível perceber na Gráfico 2. 
Gráfico 2- Oferta de disciplinas nas Universidades

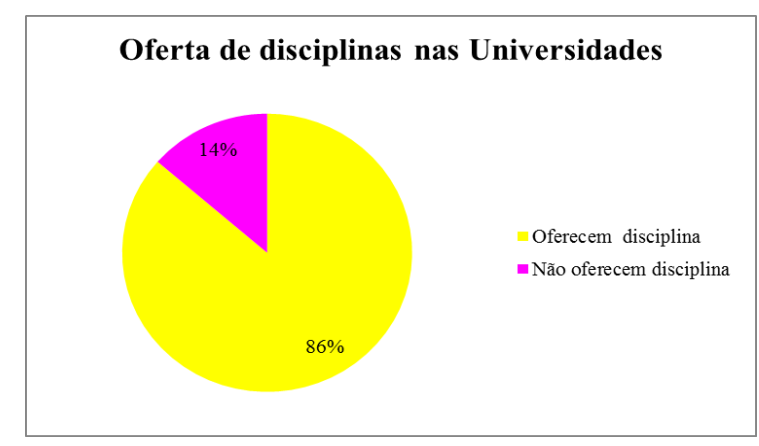

Fonte: Autoria pessoal, 2013.

Como mencionamos, em algumas universidades, 16 do total de 60 pesquisadas, não foi possível ter acesso aos currículos dos cursos de graduação ofertados nessas instituições. No entanto, dentre aquelas em que foi possível o acesso, o número de ofertas de disciplinas que abordam a sexualidade produziu um dado importante que nos mobilizou o pensamento, fazendo-nos acionar alguns rastros presentes na história que nos possibilitassem problematizar e repensar acerca desse significativo índice de oferta de disciplinas no âmbito do ensino superior.

Dentre os olhares acerca da produção da sexualidade ao longo da história, é possível perceber diferentes pontos de vista. Dentre eles, há a questão da repressão, na qual a sexualidade produziu-se como um assunto que deveria ser silenciado, mantido em segredo, algo que não deveria ser falado em todos os lugares e nem mesmo por todos os sujeitos. Para Foucault (2007), essa afirmação da repressão é a que se apresenta como mais evidente historicamente.

No entanto, avançando nas problematizações e pinçando alguns acontecimentos históricos, ou seja, lançando mão de outros olhares, ou "desconfiando dos olhares menos atentos sobre o mundo" (VEIGA-NETO, 2007a, p. 26), trazendo outras interlocuções, é possível perceber que, ao longo dos séculos, contrariamente à existência de um processo de restrição e repressão, houve uma incitação ao discurso acerca da sexualidade dos sujeitos. Contudo, é importante levar em consideração, ao olharmos para essa história, quem pode falar de sexualidade, o que pode ser dito e quais instituições são autorizadas a falar, bem como incitar esse discurso da sexualidade (FOUCAULT, 2007). 
Essa vontade de saber sobre a sexualidade, produzida ao longo dos anos na sociedade - debate traçado pelo filósofo Michel Foucault (2007) - nos possibilita compreender alguns desses movimentos do presente, a produção dessa história do presente; ou seja, a presença no ensino superior de disciplinas discutindo a sexualidade.

Com o propósito de repensar esse movimento e focando na história da sexualidade ao longo dos séculos, pode-se perceber algumas mudanças com relação à forma como esse discurso vem sendo produzido, quais conhecimentos são entendidos como legítimos, bem como quem são os sujeitos considerados autorizados a falar sobre esse assunto.

Por volta do século XVII não havia um controle das palavras, assim como as práticas não visavam o segredo; crianças e adultos misturavam-se, sem a presença fortemente marcada do que é considerado socialmente lícito ou ilícito.

Já no século seguinte é possível perceber "uma depuração - e bastante rigorosa do vocabulário autorizado" (FOUCAUL, 2007, p. 23), fazendo assim com que a sexualidade fosse encerrada em uma única teia discursiva. Então, ao invés da sexualidade sofrer um processo de restrição, o que houve foi uma incitação ao discurso, uma fermentação discursiva, "constitui-se uma aparelhagem para produzir discursos sobre o sexo, cada vez mais discursos, susceptíveis de funcionar e de serem efeito de sua própria economia" (Ibid., p. 29).

Dentre essa produção discursiva acerca da sexualidade, a segunda metade do século XVIII é marcada por um discurso que tem como foco não unicamente a moral sexual. Devido às mudanças e "problemas" sociais da época (como por exemplo, a mão de obra, o trabalho, o crescimento populacional acelerado e desordenado, entre outros elementos), torna-se importante produzir um discurso que preocupe-se também com aspectos racionais acerca da sexualidade; ou seja, já não basta apenas julgar a sexualidade, é preciso administrá-la, inseri-la "em sistemas de utilidade, regular para o bem de todos, fazer funcionar segundo um padrão ótimo" (FOUCAULT, 2007, p. 31).

Gerir, controlar e regular o sexo é o investimento para a produção de uma sociedade que passe a funcionar a partir de um padrão que almeja-se ótimo. Para tanto, emerge uma tecnologia de poder, que tem como foco a multiplicidade, a gerência de 
massas globais que estão imersas em processos que são próprios da vida, mas que afetam essa vida em sociedade - dentre eles podemos destacar o nascimento, a morte, a doença, entre outros. Essa técnica de poder, nomeada por Foucault como biopolítica, dirige-se à população, "ao homem vivo, ao homem ser vivo; no limite, se vocês quiserem, ao homem-espécie" (FOUCAULT, 2005, p. 289).

Essa tecnologia de poder que atua a partir de mecanismos regulamentadores da população não emerge de repente; já no século XVII é possível perceber alguns movimentos - por exemplo, no discurso dos juristas, que passam a discutir o direito à vida, há um investimento na vida, é preciso fazer viver e não mais fazer morrer, um dos atributos fundamentais do poder do soberano com o direito de espada (FOUCAULT, 2005).

É a partir da ineficácia desse poder soberano que emergem outras configurações das relações de poder, as quais não possuem como foco a morte, ou seja, o direito de matar que o soberano possuía como uma forma de castigo àqueles que não seguiam as leis ou não o obedeciam. É uma passagem desse poder soberano que fundamenta-se em "fazer morrer e deixar viver", para um poder que atua sobre a vida dos indivíduos, ou seja, a vida entra em jogo nas estratégias políticas e "fazer viver" passa a ser o objetivo dessas técnicas de poder.

Dentre os mecanismos que priorizam a vida, anterior às biopolíticas, vê-se aparecer um poder em que essas técnicas estão centradas no corpo individual, no homem corpo - uma tecnologia que visa disciplinar o corpo do indivíduo, trabalhando-o no nível do detalhe, "exercer sobre ele uma coerção sem folga, de mantê-lo ao nível mesmo da mecânica - movimentos, gestos, atitude, rapidez: poder infinitesimal sobre o corpo ativo" (FOUCAULT, 2008, p. 118).

Esse poder disciplinar que atua sobre o corpo não é invisibilizado ou tem sua ação suavizada com a emergência da biopolítica, pois uma técnica de poder não exclui a outra. Não estão no mesmo nível, já que uma dirige-se ao corpo individual e a outra às massas globais; entretanto, "mecanismos disciplinares do corpo e mecanismos regulamentadores da população, são articulados um com o outro" (FOUCAULT, 2005, p. 299). Ambas tecnologias de poder são constituídas a partir dessa atuação de um poder sobre a vida, são faces integrantes do biopoder. Portanto, esse poder sobre a vida 
complementa-se a partir do entrelaçamento entre o poder disciplinar, que age sobre o corpo do indivíduo, e as biopolíticas, que atuam sobre a população a fim de gerir fenômenos coletivos e, assim, governar massas globais.

O atravessamento dessas duas tecnologias de poder - o poder disciplinar e as biopolíticas - pode ser pensado a partir do dispositivo de poder que atua sobre a sexualidade, como uma estratégia de controle que, ao mesmo tempo em que atua sobre o corpo individual, também massifica, atuando sobre processos globais. A partir do controle individualizante sobre o corpo dos indivíduos no nível do detalhe, da vigilância, no que concerne a sexualidade (por exemplo, no controle à masturbação, exercido sobre as crianças tanto em âmbito familiar quanto escolar), torna-se possível uma regulação sobre "um novo corpo: um corpo múltiplo, corpo com inúmeras cabeças, se não infinito pelo menos necessariamente numerável” (FOUCAULT, 2005, p. 292). Nesse sentido, a sexualidade "está na encruzilhada do corpo e da população. Portanto, ela depende da disciplina, mas depende também da regulamentação" (Ibid., p. 300).

Para essa regulamentação da sexualidade das populações há um investimento em processos biológicos, ou seja, nas taxas de natalidade e mortalidade, na reprodução, na fecundidade, na longevidade, nas doenças, entre outros aspectos que produzem efeitos e que precisam ser controlados no âmbito das multiplicidades, das populações. É a partir dessas e de outras áreas de intervenção, visando a coletividade, que as biopolíticas irão produzir saberes para, em seguida, definir um campo de intervenção de poder, a fim de garantir a média, o equilíbrio, a regularidade.

Dentre as ações das biopolíticas, no século XVIII podemos apresentar as campanhas que visavam o aprendizado acerca da importância da higiene e da medicalização da população para garantir o controle e segurança social (FOUCAULT, 2005). Essas estratégias biopolíticas parecem produzir algumas ressonâncias no mundo contemporâneo, entretanto, com novas roupagens, a partir desse outro tempo que estamos vivenciando e também de outras necessidades que se apresentam.

Dentre as possíveis ressonâncias, a partir de algumas adaptações para a produção e ação dessa tecnologia de poder, temos nos mobilizado a pensar a emergência dessas disciplinas que discutem a sexualidade nas universidades federais, foco desse estudo, enquanto integrantes de estratégias biopolíticas. Com isso, não temos como pretensão 
encerrar a discussão acerca dessas disciplinas em uma única teia discursiva. A partir das provocações lançadas por Foucault sobre as biopolíticas e o olhar para os rastros históricos a fim de compreender o presente, é que temos buscado nos movimentar nesse estudo.

Através dessas disciplinas, a sexualidade passa a ser inserida em mecanismos, aparentemente mais sutis e economicamente mais racionais, não para julgar por meio de uma moral sexual, mas para analisar as condutas sexuais da espécie humana, as quais serão alvo de intervenção produzindo-se, assim, uma gestão que visa um padrão: o bem de todos. Para tanto, utilizam-se de algumas estratégias, dentre elas falar de sexualidade, fazer falarem os sujeitos, qualificar discursos e locutores para que falem da sexualidade enfim, é “uma incitação política, econômica, técnica, a falar do sexo" (FOUCAULT, 2007, p. 30).

Para gestão da população é preciso falar de sexualidade, e essa incitação ao discurso pode ser percebida quando olhamos para o ensino superior e encontramos, a partir das instituições pesquisadas, mais da metade delas (o equivalente a 86\%) oferecendo disciplinas que abordam essa temática. Os espaços de discussão acerca do tema da sexualidade que passam a ser produzidos a partir da emergência dessas disciplinas têm possibilitado que se fale da sexualidade e de diferentes formas, com a utilização de diferentes estratégias pedagógicas por parte dos/as professores/as que atuam nessas disciplinas, e também por diferentes discursos a partir do viés de problematização utilizado durante as aulas; ou seja, a perspectiva teórica que possibilita o subsídio para o debate e as interlocuções com determinados autores/as que discutem o tema da sexualidade.

As disciplinas - entendidas enquanto integrantes de estratégias biopolíticas, a partir de diferentes mecanismos reguladores, presentes nestes espaços em que é permitido e incitado a falar de sexualidade - têm possibilitado algumas intervenções em fenômenos os quais adquirem sentido no nível da coletividade. Dessa forma, essa fermentação discursiva da sexualidade nas universidades tem possibilitado que se garanta o equilíbrio e a média, mediante mecanismos que são globais. Por meio de discursos que enfocam os cuidados com o corpo e as doenças sexualmente transmissíveis, por exemplo, percebe-se um investimento para que os sujeitos vivam a 
sua sexualidade de forma saudável, ou seja, distante de comportamentos devassos e que promovam riscos à saúde e que poderão produzir efeitos na população. Trata-se de "levar em conta a vida, os processos biológicos do homem-espécie e de assegurar sobre eles não uma disciplina, mas uma regulamentação" (FOUCAULT, 2005, p. 294).

Entretanto, essa intervenção parece adquirir potência quando encontra-se mais entrelaçada a determinados campos de conhecimentos do que em outros. Esse aspecto pode ser percebido quando visualizamos na pesquisa que a maior oferta de disciplinas está em alguns cursos de graduação, ou seja, alguns sujeitos parecem estar mais autorizados a falar de sexualidade, ou ainda o discurso de determinadas áreas produz mais efeitos para essa regulamentação que se deseja garantir.

Das 38 universidades federais que ofertam disciplinas, essa oferta se dá em diferentes cursos de graduação, dentre os quais: Administração (2) ${ }^{2}$; Administração Pública (2); Agronomia (1); Arquivologia (1); Artes Cênicas Licenciatura (1); Artes Cênicas Habilitação Teatro Licenciatura (1); Biotecnologia (1); Ciências e Tecnologia (1); Ciências Agrárias Licenciatura (1); Ciências Biológicas Bacharelado (2) e Licenciatura (9); Ciências Contábeis (1); Ciências da Computação Licenciatura (1); Ciências da Religião Bacharelado (1) e Licenciatura (2); Ciências Sociais Bacharelado (36) e Licenciatura (41); Ciências Sociais Habilitação Antropologia Bacharelado (3); Ciências Sociais - Habilitação Sociologia Bacharelado (3); Cinema e Audiovisuais (1); Comunicação Social - Habilitação em Jornalismo (3); Ciências Naturais (2); Comunicação Social - Habilitação em Publicidade e Propaganda (2); Comunicação Social - Habilitação em Relações Públicas (2); Dança Bacharelado (1) e Licenciatura (2); Direito (6); Economia (1); Economia Doméstica Bacharelado (2); Educação do Campo Licenciatura (1); Educação do Campo - Habilitação em Linguagens Licenciatura (1); Educação Física Bacharelado (1) e Licenciatura (5); Educação Musical Licenciatura (2); Enfermagem (7); Engenharia Agrícola (1); Engenharia Civil (1); Engenharia de Alimentos (1); Engenharia de Aquicultura (1); Engenharia de Energia (1); Engenharia de Produção (1); Engenharia Mecânica (1); Estudo de Gênero e Diversidade (28); Física Licenciatura (4); Fonoaudiologia (1); Geografia Bacharelado (2) e Licenciatura (3); Gestão Ambiental (1); Gestão Pública (1); História Bacharelado (15) e

\footnotetext{
${ }^{2}$ Os números expressos entre parênteses correspondem ao número de disciplinas ofertadas encontradas nos currículos pesquisados.
} 
Licenciatura (20); Humanidades (1); Intercultural Indígena Licenciatura (1); Interdisciplinar em Ciências Humanas (1); Interdisciplinar em Educação no Campo Licenciatura (1); Letras Língua Espanhola e suas Literaturas Bacharelado (1); Letras Língua Estrangeira Inglês e Espanhol Licenciatura (2); Letras Língua Estrangeira Moderna ou Clássica Licenciatura (2); Letras Língua Portuguesa (1); Letras Língua Portuguesa e suas Literaturas Bacharelado (1); Letras Português Inglês (1); Letras Português Literatura (1); Letras Vernáculos Licenciatura (1); Letras Vernáculos Língua Estrangeira Moderna Licenciatura (2); Matemática Licenciatura (4); Medicina (3); Museologia (2); Nutrição (1); Pedagogia Licenciatura (58); Políticas Públicas Bacharelado (2); Produção Políticas e Cultural Bacharelado (1); Psicologia Bacharelado (32) e Licenciatura (6); Química Bacharelado (1) e Licenciatura (2); Relações Internacionais (1); Saúde Coletiva (5); Serviço Social (12); Sistemas de Informação (1); Sociologia Bacharelado (3); Teatro Licenciatura (1); Terapia Ocupacional (2) e Zootecnia (1).

No entanto, é possível perceber que em alguns desses cursos a oferta de disciplinas é mais significativa. Dos 82 cursos acima listados nos quais encontramos disciplinas que tratam da sexualidade sendo ofertada, 39 deles oferecem mais de uma disciplina. Já nos 43 cursos restantes, encontramos apenas uma disciplina de sexualidade sendo ofertada.

Essa fermentação discursiva, produzida a partir da interlocução entre esses campos de saber e a temática da sexualidade, produz uma teia de saberes que possibilita a intervenção e controle das multiplicidades. Centrando nosso olhar para essas áreas de conhecimento, ou seja, os cursos de graduação, vamos perceber que, em alguns deles, há um número maior de disciplinas sendo ofertadas. Refinando ainda mais essa análise, evidencia-se que alguns campos de saber, dentre eles, a Pedagogia, a Psicologia, as Ciências Sociais, entre outros, são acionados mais fortemente, apresentando uma maior oferta de disciplinas.

Esses campos de saber passam a produzir um saber técnico ${ }^{3}$, através do qual é possível implementar um gerenciamento sobre a vida das populações. A sexualidade é então o alvo de controle dessas biopolíticas, que, na contemporaneidade, adquirem mais

\footnotetext{
${ }^{3}$ Estamos utilizando a expressão "saber técnico" a partir de Foucault, entendendo como os conhecimentos de um campo que passam a constituir-se como importantes elementos na atuação dos mecanismos de regulação da biopolítica (FOUCAULT, 2005, p. 301).
} 
vitalidade devido a novas reconfigurações do tecido social. No entanto, no século XIX, o saber técnico que adquire legitimidade, segundo Foucault, para regulamentar a sexualidade da população, é o saber médico.

Através de conhecimentos científicos, a medicina vai atuar sobre processos biológicos e orgânicos produzindo-se, assim, uma relação entre a medicina e a higiene. Dentre os mecanismos reguladores que se articulam a esse saber médico podemos citar as campanhas de vacinação, amamentação, entre outras campanhas, as quais visam garantir o direito de fazer viver os indivíduos. Então, nesse período da história, a medicina apresentou-se como um "saber-poder que incide ao mesmo tempo sobre o corpo e sobre a população, sobre o organismo e sobre os processos biológicos e que vai, portanto, ter efeitos disciplinares e efeitos regulamentadores" (FOUCAULT, 2005, p. 302).

Já na contemporaneidade, pensando as disciplinas enquanto integrantes de estratégias biopolíticas, é possível perceber outras configurações acerca da produção de saberes técnicos os quais, nessa tecnologia de poder, atuam como uma política de intervenção para o controle da população.

A partir dessa significativa presença de disciplinas em alguns cursos de graduação, que tensionamentos podem ser pensados? Enquanto integrantes de estratégias biopolíticas, as disciplinas emergem, e - a partir de diferentes mecanismos regulamentadores - objetivam, com o enfoque sobre a vida, fazer viver os sujeitos, controlar a população. Ao pensarmos esses saberes técnicos que se articulam a esses mecanismos, seriam os saberes produzidos nos cursos de graduação, em que há uma oferta significativa de disciplinas, um saber potente para a produção de efeitos regulamentadores?

As biopolíticas dirigem-se aos acontecimentos aleatórios de uma população, e, para tanto, se utilizam de alguns elementos para então produzir essa regulamentação sobre as massas globais, são elas: análise de fenômenos coletivos, produção de um saber acerca desse fenômeno por meio da estatística, previsões e medições globais, interlocuções com saberes técnicos, entre outros aspectos que possibilitam que as biopolíticas definam o campo de intervenção do seu poder. 
A produção dos dados da pesquisa aponta para uma significativa oferta de disciplinas em determinadas áreas de conhecimento, o que nos possibilita pensar que essa tecnologia de poder, ao se articular a alguns saberes, passa a ter os seus efeitos de regulamentação potencializados. Estar presente de forma mais marcante em determinados cursos de graduação faz com que essas técnicas de controle e gerência da população, com relação à sexualidade, atinjam um maior alcance.

A maior oferta de disciplinas está em cursos de Licenciatura e Bacharelado. Focando nossos olhares, primeiramente, para a Licenciatura e a atuação que o profissional formado nessa modalidade terá, o trabalho com as políticas educacionais e os processos de ensino e aprendizagem, ou seja, a atuação como professor/a, percebe-se o que significa dizer que a regulamentação da sexualidade da população apresenta um alcance alargado quando associado a esse saber técnico-educacional.

Sabe-se que, ao olhar para a história da sexualidade a partir de Foucault, uma das instituições sociais em que o discurso da sexualidade organizou-se e foi disseminado foi nas escolas. Ao contrário do que muitos pensam, a instituição pedagógica não silenciou a sexualidade; "ela concentrou as formas do discurso neste tema; estabeleceu pontos de implantação diferentes; codificou os conteúdos e qualificou os locutores" (FOUCAULT, 2007, p. 36). Além disso, a sua arquitetura, a organização do pátio e do recreio, os regulamentos de disciplina e vigilância já demonstram o quanto essa instituição trata constantemente da sexualidade.

Com um discurso moralista e higienista, “do 'planejamento familiar' e de uma 'sexualidade reprodutiva"” (FURLANI, 2014), que pode ser percebido ao revisitarmos algumas literaturas pedagógicas - livros didáticos e também paradidáticos - e que visam a normalização das formas de viver a sexualidade, possibilitaram que as problematizações ficassem centradas no que é permitido e proibido falar.

Portanto, essa instituição social apresentou-se com um espaço potente para promover essas discussões, já que seu funcionamento enquanto uma maquinaria social que, por meio de práticas pedagógicas, disciplinou os corpos dos sujeitos, possibilitou também que a forma como esses sujeitos vivem a sua sexualidade fosse regulada e vigiada. 
Nesse sentido, o discurso presente na escola, o qual está relacionado à atuação do/a professor/a formado em cursos de Licenciatura de distintas universidades, interpela as formas de ser e estar dos indivíduos, moldando condutas e disciplinando comportamentos. Então, a escola é ao mesmo tempo "uma máquina de ensinar, mas também de vigiar, de hierarquizar, de recompensar" (FOUCAULT, 2008, p. 126). Essas práticas escolares produzem efeitos na coletividade, na população, que passa a ter sua sexualidade controlada, inserida em sistemas de uma economia produtiva.

Dentre os discursos utilizados pela instituição pedagógica para a produção de esquemas de intervenção em fenômenos globais, como no caso da sexualidade, destacamos o discurso da diversidade, da superação das exclusões sociais e outras exclusões de diferentes ordens. O discurso da diversidade vem adquirindo visibilidade nas discussões contemporâneas educacionais, principalmente com a implementação da SECADI, que, por meio de suas ações e projetos, tem buscado a implementação e efetivação de políticas públicas de respeito e valorização às múltiplas diversidades sexual, de gênero, raça, etnia, credo, geracional, entre outras -, apresentando-se como um importante elemento que compõe o cenário de visibilidade da sexualidade no ensino superior.

Esse discurso da diversidade também está presente em uma das estratégias do Plano Nacional de Educação, lei 13.005, de 25 de junho de 2014, com vigência de 2014 a 2024, para atingir a Meta 13, que tem como objetivo aumentar a qualidade da educação superior e ampliar o número de Mestres e Doutores do corpo de docentes efetivos das universidades.

\footnotetext{
Estratégias:

13.4) promover a melhoria da qualidade dos cursos de pedagogia e licenciaturas, por meio da aplicação de instrumento próprio de avaliação aprovado pela Comissão Nacional de Avaliação da Educação Superior CONAES, integrando-os às demandas e necessidades das redes de educação básica, de modo a permitir aos graduandos a aquisição das qualificações necessárias a conduzir o processo pedagógico de seus futuros alunos (as), combinando formação geral e específica com a prática didática, além da educação para as relações étnico-raciais, a diversidade e as necessidades das pessoas com deficiência. (BRASIL, 2014)
} 
Segundo o Plano Nacional de Educação, para pensar na melhoria da qualidade dos cursos de Licenciaturas é preciso, dentre outras estratégias, promover uma educação para a diversidade, para que os/as graduandos/as possam adquirir importantes qualificações para o seu fazer pedagógico com os/as alunos/as. Para a consolidação de uma sociedade democrática e que funcione a partir de um padrão de qualidade, no âmbito do ensino superior "é preciso promover a cultura do reconhecimento das diversidades (e aí a diversidade sexual e de gênero são centrais)" (JUNQUEIRA, 2008, p. 15).

Nesse sentido, no cenário do ensino superior, a educação para a diversidade vai desenvolver um papel importante para o enfrentamento ao sexismo e à homofobia. Ao incluir as questões das diversidades - sejam estas de gênero, sexuais, de raça, classe, etnia, credo, geração, entre outras -, estarão sendo problematizadas e desestabilizadas concepções curriculares hegemônicas que produzem e reproduzem desigualdades e hierarquias entre os grupos sociais.

Pensar uma educação para a diversidade, como a proposta do Plano Nacional de Educação (BRASIL, 2014) aprovado recentemente, possibilita que se constituam propostas pedagógicas que reconheçam e legitimem a diferença. Percebem-se, assim, as potencialidades do convívio entre segmentos sociais diferentes; quando estes sentem-se efetivamente incluídos, o resultado é a aprendizagem. A diversidade é produtiva: ela ensina e produz sujeitos para uma sociedade justa e igualitária em deveres e direitos.

Ao problematizar a questão da diversidade, a partir do Plano Nacional de Educação (BRASIL, 2014) não a estou entendendo como sinônimo de diferença. Ambos os conceitos, diversidade e diferença, possuem implicações políticas e sentidos diferentes. Enquanto que algumas políticas públicas pautadas na diversidade propõem o respeito e ações benevolentes com a diferença. A noção de diferença, por sua vez, não apenas celebra essa diferença, mas a problematiza, estimulando o impensado, é pensar a "diferença do múltiplo e não do diverso" (SILVA, 2014, p. 100).

Além disso, uma educação superior pautada no princípio da diversidade integra sujeitos que pertencem a grupos sociais que estão às margens da sociedade, os quais passam a se sentir parte da instituição escolar. Nesse sentido, a atuação do/a licenciado/a, a partir de discursos pautados na diversidade, possibilita que por meio desses saberes se 
constitua "uma técnica política de intervenção, com efeitos de poder próprios" (FOUCAULT, 2005, p. 302).

A partir de discursos que objetivam incluir/integrar, como a proposta do PNE para os cursos de Licenciatura, estaremos possibilitando que os segmentos sociais marginalizados possam se sentir parte integrante dessa sociedade; há um investimento em fazer viver, priorizar a vida, "otimizar, se vocês preferirem, um estado de vida" (FOUCAULT, 2005, p. 294).

Além disso, essa atuação dos cursos de Licenciatura que visam a ação docente se articula a outros saberes, ou seja, aqueles específicos do campo de conhecimento. A Educação Física, a Pedagogia, as Ciências Biológicas e os outros cursos de graduação em Licenciatura em que há uma significativa oferta de disciplinas, além dos saberes pedagógicos, são constituídos também pelos saberes específicos. Esse entrelaçamento possibilita, por meio de estratégias sutis e racionais, e de um saber técnico advindo da especificidade de cada um dos cursos de graduação na modalidade Licenciatura, que os mecanismos regulamentadores sejam ainda mais potencializados, garantindo a produção de esquemas de intervenção nesses fenômenos globais.

Já com relação aos cursos de Bacharelado, os quais proporcionam aos/às alunos/as que cursam a graduação nessa modalidade, uma formação em determinado campo de saber para a atuação em diferentes áreas do mercado de trabalho, também apresentaram-se, na produção dos dados da pesquisa, com um número significativo de ofertas de disciplinas que abordam a sexualidade no ensino superior. Essa oferta reflete o quanto as transformações de diferentes ordens sociais, econômicas, culturais, políticas e históricas têm exigido uma "flexibilização na nossa forma de ser, viver e estar no mundo como pessoa e como profissional" (HENNING, 2009, p. 180).

Pensar acerca da sexualidade, das múltiplas formas de ser homem e mulher na nossa sociedade, as identidades de gênero e sexuais, os aspectos históricos e políticos do gênero, entre outras questões debatidas nas disciplinas, são debates não somente do âmbito escolar, como é possível perceber ao analisar suas ementas. Esse novo tempo, em que essas questões da sexualidade passam a adquirir uma maior visibilidade, nos impulsiona a pensar e promover outras formas de ser e estar na contemporaneidade, diferentes das formas convencionais dadas pela moral sexual, por exemplo. 
A atuação de um bacharel vai se dar em diferentes instituições sociais, as quais são espaços educativos, "locais que ensinam e possuem uma pedagogia, ou seja, espaços sociais implicados na produção e no intercâmbio de significados, tais como: universidade; escola; mídia; instituições religiosas, jurídicas, de saúde e de trabalho, entre outros" (RIBEIRO; RIZZA; ÁVILA, 2014, p. 138). Nesse sentido, o debate de questões relacionadas à sexualidade possibilita que "uma teia de discursos, de saberes, de análises e de injunções o investiram" (FOUCAULT, 2007, p. 33), inserindo-a em um sistema de utilidade e regulação para que funcione a partir de uma média, de um ponto de equilíbrio.

Então, a presença de discussões acerca da sexualidade em cursos de bacharelado das universidades pesquisadas, assim como nos cursos de licenciatura, também tem potencializado a atuação das disciplinas, nas quais essa temática tem emergido, enquanto integrantes de estratégias biopolíticas. A partir do entendimento de que nos produzimos não somente em espaços formais de educação, mas que os diferentes espaços pelos quais transitamos também ensinam, possuem uma pedagogia que nos interpela a todo momento, nos mobilizando a pensar e a nos (re)produzirmos constantemente, é que as graduações na modalidade Bacharelado têm se apresentado como estratégia potente na atuação das disciplinas.

Sendo assim, os saberes técnicos produzidos, tanto pelo Bacharelado quanto pela Licenciatura, apresentam-se, ao olharmos para as disciplinas como integrante de estratégias biopolíticas, não como elementos primordiais, mas como aqueles que possuem um grau significativo de importância, já que "o saber é um dos componentes de definição da atuação do poder no mundo moderno" (DREYFUS; RABINOW, 2010, p. 267). Esses saberes então potencializam e ampliam o alcance dessa tecnologia de poder que atua sobre a regulamentação da população.

Para gerir esse controle sobre a população e exercer um poder para regular as condutas e governar os indivíduos, é preciso conhecer esses indivíduos; sendo assim, o poder está estreitamente relacionado com o saber, assim como o saber não está isento dos efeitos do poder. $E$ assim também se dá a produção dos currículos das universidades quando pensamos a emergência das disciplinas que discutem sexualidade, ou seja, “o currículo, como corporificação de saber, está estreitamente vinculado ao poder" (SILVA, 2008, p. 197). 
Ao nos referirmos ao poder, não o estamos entendendo como estando presente em um ponto específico do tecido social, ou ainda como algo que se detém, tendo de um lado os que têm poder e, de outro, aqueles que não o detém. Segundo Foucault (2007a, p. 8), o poder "produz coisas, induz ao prazer, forma saber, produz discurso. Deve-se considerá-lo como uma rede produtiva que atravessa todo o corpo social muito mais do que uma instância negativa que tem por função reprimir”.

O poder está implicado na produção do currículo por meio da seleção do que é ou não conhecimento legítimo de estar presente no mesmo, ou como chamou Julia Varela (2008), pela pedagogização dos conhecimentos. Segundo a autora, a partir da emergência da noção de infância tal como conhecemos na contemporaneidade, de que é preciso separar as crianças dos adultos para que as mesmas fossem protegidas e preservadas, é que houve "a necessidade de controlar os saberes que iam transmitir e de organizar esses saberes de tal forma que se adequassem às supostas capacidades infantis" (VARELA, 2008, p. 88).

A partir dessas relações de poder/saber inscritas no currículo, desse controle sobre aquilo que está incluído ou que está às margens desse artefato cultural, é que podemos pensar na forma como tem se dado a oferta de disciplinas que discutem a sexualidade nas universidades. A partir do campo teórico sobre o qual essa pesquisa está alicerçada, estamos entendendo o currículo, revistas, propagandas, filmes, entre outros, como artefatos culturais, ou seja, como produções culturais permeadas de saberes e representações, os quais vão ensinando modos de ser e estar no mundo, construindo e reproduzindo significados sociais, a partir das pedagogias culturais (STEINBERG, 1997), presentes nesses artefatos.

Na pesquisa, nos deparamos com uma significativa oferta de disciplinas no ensino superior; no entanto, essa oferta tem se dado, na sua maioria, de forma optativa, como podemos perceber na Gráfico 3. 
Gráfico 3- Disciplinas obrigatórias e optativas nas Universidades

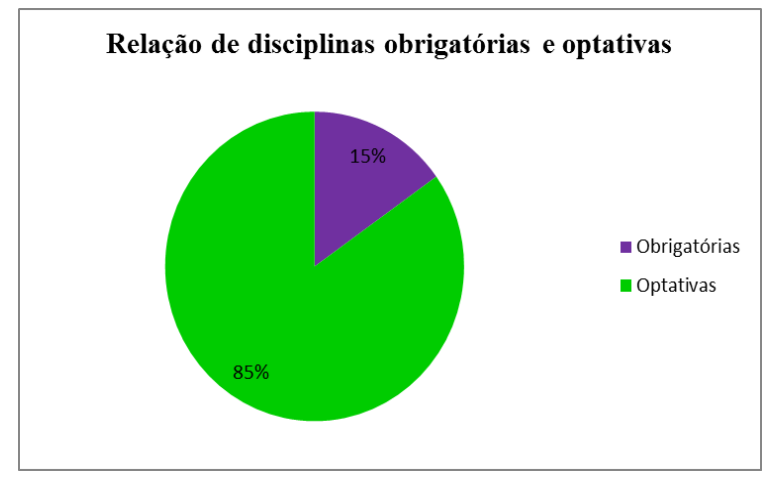

Fonte: Autoria pessoal, 2013.

Das 384 disciplinas ofertadas, $325^{4}$ são optativas, o equivalente a $85 \%$, e somente 58 são obrigatórias, cerca de $15 \%$ - sendo que dessas, 17 estão presentes no curso de Estudo de Gênero e Diversidade Bacharelado, da Universidade Federal da Bahia - UFBA, no qual o foco de discussão no curso de graduação de maneira geral está nas questões que envolvem o gênero, a sexualidade, a diversidade, entre outras. Então, ao traçar outro olhar sobre os dados e suprimindo esse curso de graduação, que se apresentou como uma ruptura ao que vinha sendo produzido na pesquisa, o número de disciplinas obrigatórias diminui ainda mais.

Com isso, não temos como pretensão traçar uma problematização que vá ao encontro da obrigatoriedade do debate acerca da sexualidade nas universidades. Ao contrário, nossa proposta não é defender essa posição, mas refletir acerca das relações de poder/saber presentes nesses currículos; ou seja, é pensar o quanto que é por meio de um "processo de intervenção social que certos conhecimentos acabam fazendo parte do currículo e outros não" (SILVA, 2007, p. 148), produzido assim algumas desigualdades sociais.

Ao instituir espaços de discussão como disciplinas optativas, será a sexualidade uma temática problematizada com os/as acadêmicos/as no ensino superior? As disciplinas optativas apresentam assuntos que complementam os componentes curriculares obrigatórios; os/as alunos/as têm a possibilidade de cursá-las ou não. Nesse sentido, a sexualidade, embora componha os currículos do ensino superior, está às margens desse

\footnotetext{
${ }^{4}$ Desse total de ofertas, estão às disciplinas que são ofertadas para mais de um curso de graduação da universidade, sendo assim contabilizadas mais de uma vez.
} 
mesmo currículo, pois os conhecimentos legítimos, os considerados válidos de serem debatidos, estão nos cursos de graduação como componentes curriculares obrigatórios.

Ao examinarmos essas relações de poder/saber, centramos nosso olhar para essa seleção de conhecimentos no currículo, esse estatuto de saberes que pode estar presente em discussões nas instituições educacionais quando o assunto em pauta for a sexualidade, e assim nos questionamos:

Quais conhecimentos estão incluídos e quais conhecimentos estão excluídos do currículo? Quais grupos sociais estão incluídos - e de que forma estão incluídos - e quais grupos sociais estão excluídos? Como resultado dessas divisões, dessas inclusões e exclusões, que divisões sociais - de gênero, raça, classe - são produzidas ou reforçadas? (SILVA, 2008, p. 197)

Os discursos que vêm produzindo o currículo estabelecem o que é certo e o que é errado, quais os conhecimentos legítimos - conhecimentos produzidos pela ciência - e quais os conhecimentos do senso comum - entre outras verdades discursivas, as quais interpelam os sujeitos e os constituem. Segundo Foucault, “a 'verdade' é centrada na forma do discurso científico e nas instituições que o produzem" (FOUCAULT, 2007a, p. 13), ou seja, o conhecimento científico é o que a sociedade considera legítimo e, por esse motivo, é sobre este que a escola ancorará seus entendimentos.

O conhecimento científico é aquele autorizado e legítimo de estar presente no currículo e, além disso, esse artefato determina quem está autorizado a falar e também o que pode ser dito. Então, “o conhecimento inscrito no currículo não pode, assim, ser separado das regras de regulação e controle que definem suas formas de transmissão" (SILVA, 2008, p. 202).

Com relação à sexualidade, a partir da fermentação discursiva acerca dessa temática no século XVIII, algumas estratégias de regulação e controle sobre esse discurso foram estabelecidas. Na contemporaneidade, com as disciplinas que discutem sexualidade nas universidades, podemos perceber esse processo de seleção do discurso adquirindo vitalidade; estamos falando dos sujeitos que atuam na docência dessas disciplinas, os quais parecem estar autorizados a falar. 
Quem está autorizado a falar: são professores/as, que pesquisam e estão vinculados a grupos de pesquisas que tem como foco central a sexualidade nas universidades que passam a ministrar as disciplinas, ou seriam professores/as que já estão atravessados/as pelas questões que envolvem a sexualidade que têm atuado nesses espaços?

Mobilizadas por esse questionamento, produzimos um entrecruzamento nos dados, ou seja, a partir das 60 universidades federais pesquisadas fomos em busca dos grupos de pesquisa vinculados a essas instituições, a fim de analisar se os/as docentes que atuam nessas disciplinas são sujeitos que já vêm pensando acerca dessas temáticas, ou seja, que estão inseridos/as em um grupo de pesquisa. Para tanto, navegamos no Diretório dos Grupos de Pesquisa no Brasil vinculados ao Conselho Nacional de Desenvolvimento Científico e Tecnológico (CNPq) e estabelecemos alguns critérios, são eles: o encontro nessa busca com algumas palavras-chave no nome, na descrição e na linha de pesquisa dos grupos. As palavras-chave foram: gênero; sexualidade; diversidade; educação sexual; orientação sexual - as mesmas utilizadas no mapeamento no site das universidades para encontrar as disciplinas.

Nesse outro movimento, encontramos um número significativo de grupos de pesquisa, um total de 528; entretanto, ainda não era possível saber se existia essa relação grupo de pesquisa/oferta de disciplina. Então, fomos em busca dos currículos cadastrados na Plataforma Lattes dos/as pesquisadores/as líderes de cada um dos grupos de pesquisa encontrados.

No Currículo Lattes é possível encontrar os registros das atividades/ações desenvolvidas por estudantes e pesquisadores/as, dentre elas a atuação no âmbito do ensino nas universidades. Sendo assim, das 60 instituições pesquisadas, em 20 delas encontramos esse entrelaçamento, ou seja, a disciplina que discute a sexualidade estava sendo ministrada por sujeitos que já vêm pensando essas questões e entendem a importância desse debate em diferentes espaços sociais e instituições.

Em algumas universidades em que há mais de um grupo de pesquisa debatendo a questão da sexualidade é possível encontrar a oferta de disciplinas nesse diálogo entre esses grupos, como, por exemplo, na Universidade Federal de Uberlândia (UFU), onde a mesma disciplina, "Gênero como categoria de análise social” é oferecida em dois cursos 
de graduação - Ciências Sociais Bacharelado e Licenciatura -, e por dois grupos de pesquisa: o Grupo de Estudos e Pesquisas de Gênero: Relações sociais, representações e subjetividades (GEPEGRES) e o Núcleo de Estudos de Gênero - (NEGUEM).

Esse entrecruzamento dos dados, a partir da relação entre a oferta de disciplinas e os grupos de pesquisa vinculados às instituições de ensino superior nos possibilita pensar acerca das relações de poder que estão implicadas no currículo, no que tange a seleção de conhecimento. Entendemos os currículos como "território de produção, circulação e consolidação de significados" (COSTA, 2005, p. 38); sendo assim, é por meio dos atravessamentos das relações de poder que o currículo exclui e inclui conhecimento, determina quais saberes são legítimos e ilegítimos, produzindo assim desigualdades entre diferentes grupos sociais.

No entanto, esse dado produzido na pesquisa nos mobiliza a pensar que os/as professores/as das disciplinas que discutem a sexualidade nas universidades têm promovido algumas rupturas nessa organização e produção do currículo. A atuação dos/as líderes de pesquisa nessas disciplinas impulsiona essa arena curricular em que o que está em disputa é essa fixação de visões de mundo.

Pertencer a um grupo de pesquisa que discute as questões de sexualidade e também ser o sujeito que ministra, nas universidades, disciplinas acerca dessa temática possibilita alguns desdobramentos nesses currículos do ensino superior, como a luta pela consolidação do significado sobre a importância das universidades promoverem o debate acerca da sexualidade. Traçando um olhar que visa problematizar a sexualidade e sua relação com a educação, independente da modalidade de ensino, é possível perceber que essa temática "se constituiu numa questão polêmica no espaço escolar, e por longo tempo os currículos escolares mantiveram-se distantes dessa discussão explicitamente" (FURLANI, 2014).

Nesse sentido, essa relação entre os grupos de pesquisa e a oferta de disciplinas nas universidades expressa os movimentos que vêm sendo feitos por parte de alguns sujeitos de diferentes segmentos sociais - nesse caso de professores/as universitários e/ou pesquisadores/as vinculados a grupos de pesquisa - a fim de que as problematizações que envolvem as pedagogias das sexualidades adquiram visibilidade na contemporaneidade. 


\section{Apenas algumas considerações para não encerrar as discussões}

A partir das discussões empreendidas, temos como pretensão construir in-determinações, ou seja, não desejamos terminar e encerrar as problematizações em uma teia discursiva, assim como não almejamos de-terminar o que possa ser dito. Esperamos que "o dizer não se acabe e nem se termine" (LARROSA, 2010, p. 142), que outros olhares e dizeres possam ser lançados acerca dos dados produzidos. É nesse sentido que são apenas algumas considerações, mas não considerações finais, para que as discussões não se encerrem e para que outros olhares possam surgir com relação a essa emergência de disciplinas que tratam da sexualidade no ensino superior.

Por meio da proposta inicial dessa escrita, de apresentar um panorama acerca da emergência de disciplinas que discutem a sexualidade no âmbito das universidades federais brasileiras, através do levantamento que denominamos mapeamento, foi possível pensar acerca das discussões traçadas por Foucault sobre a tecnologia de poder que tem como objetivo a regulamentação da população. Pensar essas disciplinas enquanto integrantes de estratégias biopolíticas nos fez perceber o quanto essa tecnologia de poder vem adquirindo cada vez mais vitalidade e visibilidade na contemporaneidade.

Essa regulação e esse governo das populações promovido pelas biopolíticas não estão presentes em qualquer instituição, pensamos em olhar para essas disciplinas enquanto integrantes de estratégias biopolíticas, pois entendemos que "a educação é certamente um desses dispositivos, central na tarefa de normalização, disciplinarização, regulação e governo das pessoas e das populações" (SILVA, 2008a, p. 252). Com isso, não estamos entendendo que a prática pedagógica dos/as professores/as esteja pautada apenas nesse processo de controle e governo dos sujeitos. A educação está atravessada por outros elementos, e dentre eles podemos destacar, por exemplo, o processo de ensino e aprendizagem como um aspecto fortemente problematizado e que também compõe o campo educacional e não somente a disciplinarização e regulação.

Através dos dados que emergiram, a partir da produção do mapeamento nas universidades federais brasileiras credenciadas no site do Ministério da Educação, 
também foi possível pensar as relações de poder e saber, os enfrentamentos produzidos na arena política em que se constituem os currículos do ensino superior.

A partir das discussões empreendidas nesse estudo, não buscamos ressaltar a importância da existência de disciplinas no ensino superior que discutam a sexualidade e outras questões que envolvem essa temática, como o gênero, a diversidade, entre outros aspectos. A partir de alguns rastros presentes na história da sexualidade, de um diagnóstico dessa atual situação e da produção do mapeamento, temos buscado compreender o presente, ou seja, os efeitos da emergência, na contemporaneidade, de disciplinas que discutem a sexualidade no âmbito das universidades federais no Brasil. 


\section{Referências}

BRASIL. Ministério da Educação e Cultura. Instituições de educação superior e cursos cadastrados. Brasília: e-MEC, 2012. Disponível em: <http://emec.mec.gov.br/>. Acesso em: 5 nov. 2012.

BRASIL. Ministério da Educação. Plano Nacional de Educação - PNE. Brasília: MEC, 2014. Disponível em:

<http://www.planalto.gov.br/CCIVIL_03/_Ato2011-2014/2014/Lei/L13005.htm>. Acesso em: 4 set. 2014.

COSTA, Marisa Vorraber. Currículo e política cultural. In: COSTA, Marisa Vorraber (Org.). 0 currículo nos limiares do contemporâneo. Rio de Janeiro: DP\&A, 2005. p. 37-68.

DREYFUS, Hubert Lederer; RABINOW, Paul. Michel Foucault: uma trajetória filosófica para além do estruturalismo e da hermenêutica. 2. ed. Rio de Janeiro: Forense Universitária, 2010. 348 p.

FOUCAULT, Michel. Em defesa da sociedade: curso no Collège de France (1975-1976). São Paulo: Martins Fontes, 2005. 382 p.

FOUCAULT, Michael. História da sexualidade I: a vontade de saber. 18. ed. São Paulo: Graal, 2007. $176 \mathrm{p}$.

FOUCAULT, Michael. Microfísica do poder. 24. ed. São Paulo: Graal, 2007a. 288 p. FOUCAULT, Michael. Vigiar e punir. 35. ed. Petrópolis: Vozes, 2008. 295 p.

FURLANI, Jimena. Educação sexual: quando a articulação de múltiplos discursos possibilita sua inclusão curricular. Revista Perspectiva, v.26, n.1, 2008. Disponível em: $<$ https://periodicos.ufsc.br/index.php/perspectiva/article/view/2175795x.2008v26n1p283/9 573>. Acesso em: 15 jul. 2014.

HENNING, Paula Corrêa. Educação e inclusão: garantia de direitos na modernidade líquida.Revista Educação e Realidade, Porto Alegre, v. 33, n. 34, p. 177-190, set./dez. 2009.

JUNQUEIRA, Rogério Diniz. Corpos, gêneros e sexualidades na escola: por uma educação promotora do reconhecimento da diversidade sexual e de gênero. In: RIBEIRO, Paula Regina Costa; RIZZA, Juliana Lapa; MAGALHÃES, Joanalira Corpes; QUADRADO, Raquel Pereira (Org.). Educação e sexualidade: identidade, famílias, diversidade sexual, prazeres, desejos, preconceitos, homofobia... 2. ed. Rio Grande: FURG, 2008. p. 12-26.

LARROSA, Jorge. Sobre a lição. In: LARROSA, Jorge. Pedagogia profana: danças, piruetas e mascaradas. 5. ed. Belo Horizonte: Autêntica, 2010. p. 139-146.

RIBEIRO, Paula Regina Costa; RIZZA, Juliana Lapa; ÁVILA, Dárcia Amaro. Gênero e sexualidade no Ensino Superior: reflexões sobre a produção de possíveis heterotopias. In: 
MAGALHÃES, Joanalira Corpes; RIBEIRO, Paula Regina Costa (Org.). Educação para a sexualidade. Rio Grande: Editora da FURG, 2014. p. 129-141.

SILVA, Tomaz Tadeu da. Documentos de identidade: uma introdução as teorias do currículo. Belo Horizonte: Autêntica, 2007.156 p.

SILVA, Tomaz Tadeu da. Currículo e identidade social: territórios contestados. In: SILVA, Tomaz Tadeu da (Org.). Alienígenas na sala de aula. Petrópolis: Vozes, 2008. p. 190-207.

SILVA, Tomaz Tadeu da. O adeus às metanarrativas educacionais. In: SILVA, Tomaz Tadeu da (Org.). O sujeito da educação: estudos foucaultianos. Petrópolis: Vozes, 2008a. p. 247258.

SILVA, Tomaz Tadeu da. A produção social da identidade e da diferença. In: SILVA, Tomaz Tadeu da (Org.). Identidade e diferença: a perspectiva dos estudos culturais. Petrópolis: Vozes, 2014. p. 73-102.

STEINBERG, Shirley. Kindercultura: a construção da infância pelas grandes corporações. In: SILVA, Luiz H., AZEVEDO, José C. de; SANTOS, Edmilson S. dos. (Org.). Identidade social e a construção do conhecimento. Porto Alegre: Prefeitura Municipal de Porto Alegre, Secretaria de Educação, 1997. p. 98-145.

VARELA, Julia. O estatuto do saber pedagógico. In: SILVA, Tomaz Tadeu da (Org.). 0 sujeito da educação: estudos foucaultianos. Petrópolis: Vozes, 2008. p. 87-96.

VEIGA-NETO. Foucault \& a educação. 2. ed. Belo Horizonte: Autêntica, 2007.160 p.

VEIGA-NETO, Alfredo. Olhares. In: COSTA, Marisa Vorraber (Org.). Caminhos investigativos I: novos olhares na pesquisa em educação. 3. ed. Rio de Janeiro: Lamparina, 2007a. p. 23 - 38.

Recebido em: 04/03/2016 Aprovado em: 29/04/2016

Universidade do Estado de Santa Catarina - UDESC Programa de Pós-Graduação em Educação - PPGE Revista Linhas Volume 17 - Número 34 - Ano 2016 revistalinhas@gmail.com 